Pacific Journal of Mathematic 


\section{EXCEPTIONAL REAL LEHMER SEQUENCES}

\section{K. DuRsT}

1. Introduction. If $L$ and $M$ are rational integers and $L$ is positive, the sequence

$$
(P): \quad P_{0}, P_{1}, P_{2}, \cdots, P_{n}, \cdots
$$

is called the Lehmer sequence generated by

$$
f(z)=z^{2}-L^{1 / 2} z+M,
$$

if

$$
\begin{aligned}
P_{n} & =\left(\alpha^{n}-\beta^{n}\right) /(\alpha-\beta), \text { for } n \text { odd, } \\
& =\left(\alpha^{n}-\beta^{n}\right) /\left(\alpha^{2}-\beta^{2}\right), \text { for } n \text { even, }
\end{aligned}
$$

where $\alpha, \beta$ are the roots of $f(z)=0$. Since $P_{0}=0, P_{1}=1$ and the remaining terms of $(P)$ satisfy the recursion relations

$$
\begin{aligned}
P_{2 n} & =P_{2 n-1}-M P_{2 n-2} \\
P_{2 n+1} & =L P_{2 n}-M P_{2 n-1},
\end{aligned}
$$

it is clear that every Lehmer sequence is a sequence of rational integers. In Lehmer [1], $P_{n}$ is denoted by $\bar{U}_{n}$.

The sequence $(P)$ is called real if $K=L-4 M$, the discriminant of $f(z)$, is positive. An index $n$ greater than 2 is called exceptional if each prime dividing $P_{n}$ also divides a term $P_{m}$, where $0<m<n$. The sequence $(P)$ is called exceptional if it contains a term whose index is exceptional.

This paper continues the classification of exceptional real Lehmer sequences begun by Morgan Ward [2]. The main result is the following theorem.

THEOREM 1.0. For real Lehmer sequences, the only possible exceptional indices are six and twelve. Twelve is exceptional only in the sequences determined by

$$
L=1, M=-1 \text { and } L=5, M=1 .
$$

Six is exceptional if and only if

$$
L=-3 K+2^{s+2}, M=-K+2^{s},
$$

Received November 7, 1958. 
where $s \geqq 1,2^{s+2}>3 K$, and $K$ is odd and positive. Thus for each odd positive value of $K$, there are infinitely many exceptional Lehmer sequences.

For $K=5, s=2$, and for $K=1, s=1$, the expressions for $L$ and $M$ in Theorem 1.0 reduce to

$$
L=1, M=-1 \text { and } L=5, M=1 \text {, }
$$

respectively. The first of these Lehmer sequences is the Fibonacci sequence $F_{n}$, and the second is closely related to the Fibonacci sequence since $P_{2 n}=F_{2 n}$. These two exceptional sequences (the only real Lehmer sequences in which both six and twelve are exceptional) were found by Ward. It has long been known that the Lucas sequence generated by $z^{2}-3 z+2$ has six as its only exceptional index (Ward [2]); on the other hand, the Lehmer sequence generated by the same polynomial has no exceptional indices. (Cf. Theorem 2.0.) In Theorem 1.2 of [2], "eighteen" should be deleted, since $F_{18}=2^{3} .17 .19$.

In this discussion, $L$ and $M$ are assumed to be coprime. Ward has shown that this assumption leads to no loss of generality.

2. Apparition and repetition of primes in Lehmer sequences. If $p$ is a rational prime, and if $p \mid P_{k}$ but $p \nmid P_{m}$ for $0<m<k$, then $k$ is called the rank of apparition of $p$ in $(P)$. The theorem governing the apparition of rational primes in Lehmer sequences is the following law of apparition given by Lehmer [1] in a slightly different form.

THEOREM 2.0. If $k$ is the rank of apparition of $p$ in the sequence $(P)$, then

$$
k=2 p \quad \text { if } \quad p \mid L
$$

and

$$
k \mid p-\sigma \varepsilon \quad \text { if } \quad p \nmid 2 L M,
$$

where $\sigma=(K / p), \varepsilon=(L / p)$ are Legendre symbols. If $p=2$, then $k=3$ for $L$ odd, and $k=4$ for $L$ even. If $p \mid M$, then $p$ divides no term of $(P)$, save $P_{0}=0$.

Since each Lehmer sequence is a divisibility sequence (Lehmer [1]), the fundamental property of the appearance of primes is given by the following theorem.

THEOREM 2.1. If $k$ is the rank of apparition of $p$ in $(P)$, then $p \mid P_{n}$ if and only if $k \mid n$.

Given $L$ and $M$ and a prime $p$ dividing $(P)$, the determination of the exact power of $p$ dividing $P_{k}$ is a generalization of the unsolved 
problem of the quotients of Fermat; consequently it would appear to be premature to ask for an answer to this question. Theorem 2.1 prescribes those terms, other than $P_{k}$, containing the factor $p$, and the law of repetition tells the exact power of $p$ dividing $P_{k m}$, provided the highest power of $p$ dividing $P_{k}$ is supposed known. However, the law of repetition (as given by Lehmer [1]) fails to cover the repetition of the prime 2 in the case in which 2 initially appears to the first power. For the problem at hand a detailed study of this case is required and will be found in $\S 3$.

Let $p^{t} \| P_{n}$ mean that $p^{t} \mid P_{n}$ but $p^{t+1} \nmid P_{n}$. Then Lehmer's law of repetition may be stated as follows.

THEOREM 2.2. If $k$ is the rank of apparition of $p$ in $(P), p^{t} \| P_{k}$ for $t \geqq 1, p^{t} \neq 2$, and $(p, l)=1$, then $p^{r+t} \| P_{p^{r} k l}$.

Following Ward [2], the associated sequence $(Q)$ is defined as follows:

$$
Q_{0}=0, Q_{1}=1, Q_{2}=1 \text {, and } Q_{n}=\beta^{\phi(n)} F_{n}(\alpha / \beta) \text { for } n \geqq 3 \text {, }
$$

where $F_{n}(z)$ is the $n$th cyclotomic polynomial, of degree $\phi(n) . Q_{n}$ is an integer for each $n \geqq 0$ and $P_{n}=\Pi Q_{a}$, the product being taken over all divisors $d$ of $n$. Expressed in terms of $L$ and $M$, the $Q^{\prime}$ s are homogeneous polynomials of degree $\frac{1}{2} \phi(n)$. A few of the $Q^{\prime}$ s are exhibited here for purposes of reference:

$$
\begin{gathered}
Q_{3}=L-M, Q_{4}=L-2 M, Q_{6}=L-3 M, \\
Q_{8}=L^{2}-4 L M+2 M^{2}, Q_{12}=L^{2}-4 L M+M^{2} .
\end{gathered}
$$

3. The appearance of powers of 2. The cases in which 2 appears in $(P)$ are given by

(i) $L=2 l+1, \quad M=2 m+1$,

(ii) $L=2 l, \quad M=2 m+1$.

In case (i) the rank of 2 is 3 ; indeed

$$
Q_{3}=L-M=2(l-m) \equiv 0\left(\bmod 2^{t}\right), \quad t \geqq 1,
$$

whenever $l \equiv m\left(\bmod 2^{t-1}\right)$. Suppose $l=m+2^{t-1} n$. Then

$$
\begin{aligned}
Q_{6} & =L-3 M=2^{t} n-2 M \equiv 2(\bmod 4), \text { if } t>1 \\
& =2(n-M), \text { if } t=1 .
\end{aligned}
$$

Hence, if $2 \| Q_{3}$, then $Q_{6} \equiv 0\left(\bmod 2^{s}\right), s \geqq 1$, whenever $n \equiv M\left(\bmod 2^{s-1}\right)$. Thus, for suitably chosen $L$ and $M$, any given power $2^{t}$ of 2 may be made to divide $Q_{3}$. As the law of repetition requires, if $t>1$, then $2 \| Q_{6}$. On the other hand, if $2 \| Q_{3}$, then $L$ and $M$ may be chosen 
so that any given power $2^{s}$ will divide $Q_{6}$; this is the case not covered by Theorem 2.2. Since $L$ and $M$ are odd,

$$
Q_{12}=Q_{3}^{2}-2 L M \equiv 2(\bmod 4),
$$

whether $t=1$ or $t>1$.

In case (ii) the rank of 2 is 4 ; and

$$
Q_{4}=L-2 M=2(l-M) \equiv 0\left(\bmod 2^{\imath}\right), t \geqq 1,
$$

whenever $l \equiv M\left(\bmod 2^{t-1}\right)$. But

$$
Q_{8}=L^{2}-4 L M+2 M^{2} \equiv 2(\bmod 4)
$$

since $L$ is even and $M$ is odd. In this case $2 \| Q_{8}$, whatever power of 2 may divide $Q_{4}$.

The following lemma completes the discussion of the repetition of 2 .

Lemma 3.0. If $2^{t} \| P_{2 n}$ and $2^{t+1} \| P_{4 n}$, then $2^{t+2} \| P_{8 n}$.

Proof. For $m$ even, $S_{m}=\alpha^{m}+\beta^{m}$ is a rational integer. Because $P_{4 n}=P_{2 n} S_{2 n}$, the hypotheses imply that $2 \mid S_{2 n}$. But $S_{4 n}=S_{2 n}^{2}-2 M^{2 n} \equiv 2$ $(\bmod 4)$, hence $2^{t+2} \| P_{8 n}$, since $P_{8 n}=P_{4 n} S_{4 n}$.

From Lemma 3.0 it follows that when $n$ exceeds $k$, the rank of 2 , then $2 \| Q_{n}$ implies $2 \| Q_{2 n}$.

The results of the present section show that Lemmas 3.3 and 3.4 in Ward [2] need not hold for $n=6$ when $Q_{6}$ is even.

4. Sequences in which six is exceptional. The only cases left open in Ward's analysis are those in which $Q_{6}$ is even and, hence, $K, L$ and $M$ are odd.

Lemma 4.0. For $K$ odd, six is exceptional if and only if $L=$ $-3 K+2^{s+2}>0, M=-K+2^{s}$, where $s \geqq 1$.

Proof. Let $L=2 l+1, M=2 m+1$, then $Q_{3}=L-M=2(l-m)$ and $Q_{6}=L-3 M=2(l-3 m-1)$. Six is exceptional if and only if

$$
l-3 m-1=2^{s-1} \delta \text { where } l-m=d \delta \text {, and } s \leqq 1 \text {. }
$$

But $2^{s-1} \delta=l-3 m-1=d \delta-M$, so $M=\delta\left(d-2^{s-1}\right)$, and $L=2 l+1=$ $M+2 d \delta$. Since $(L, M)=1, \delta$ must be \pm 1 . Thus the conditions become

$$
L= \pm\left(3 d-2^{s-1}\right), M= \pm\left(d-2^{s-1}\right) \text {. }
$$

Since $K=L-4 M, K= \pm\left(3.2^{s-1}-d\right)$, or $d=3.2^{s-1} \pm K$, givng

$$
L=-3 K \pm 2^{s+2}, M=-K \pm 2^{s} .
$$


Because $L>0$, the upper sign must be chosen and $s$ must be taken large enough to make $2^{s+2}>3 K$.

The values of $L$ and $M$ given in Lemma 4.0 yield $Q_{3}=L-M=$ $2\left\{3.2^{s}-K\right\}$ and $Q_{6}=L-3 M=2^{s}$.

Theorem 1.0 now follows from Lemma 4.0 and Ward's results.

\section{REFERENCES}

1. D. H. Lehmer, An extended theory of Lucas' functions, Ann. of Math. (Second Series), 31, (1930), 419-448.

2. Morgan Ward, The intrinsic divisors of Lehmer numbers, Ann. of Math. (Second Series), 62, (1955), 230-236.

The Rice Institute 



\section{PACIFIC JOURNAL OF MATHEMATICS}

\section{EDITORS}

\section{David Gilbarg}

Stanford University

Stanford, California

\section{R. A. Beaumont}

University of Washington

Seattle 5 , Washington

\author{
A. L. Whiteman
}

University of Southern California Los Angeles 7, California

L. J. Paige

University of California

Los Angeles 24, California

\author{
E. F. BECKENBACH \\ C. E. BURGESS \\ E. HEWITT \\ A. HORN
}

\author{
V. GANAPATHY IYER \\ R. D. JAMES \\ M. S. KNEBELMAN \\ L. NACHBIN
}

ASSOCIATE EDITORS
I. NIVEN

T. G. OSTROM

H. L. ROYDEN

M. M. SCHIFFER
E. G. STRAUS

G. SZEKERES

F. WOLF

K. YOSIDA

\section{SUPPORTING INSTITUTIONS}

\author{
UNIVERSITY OF BRITISH COLUMBIA \\ CALIFORNIA INSTITUTE OF TECHNOLOGY \\ UNIVERSITY OF CALIFORNIA \\ MONTANA STATE UNIVERSITY \\ UNIVERSITY OF NEVADA \\ OREGON STATE COLLEGE \\ UNIVERSITY OF OREGON \\ OSAKA UNIVERSITY \\ UNIVERSITY OF SOUTHERN CALIFORNIA
}

\author{
STANFORD UNIVERSITY \\ UNIVERSITY OF TOKYO \\ UNIVERSITY OF UTAH \\ WASHINGTON STATE COLLEGE \\ UNIVERSITY OF WASHINGTON \\ * * * \\ AMERICAN MATHEMATICAL SOCIETY \\ CALIFORNIA RESEARCH CORPORATION \\ HUGHES AIRCRAFT COMPANY \\ SPACE TECHNOLOGY LABORATORIES
}

Mathematical papers intended for publication in the Pacific Journal of Mathematics should be typewritten (double spaced), and the author should keep a complete copy. Manuscripts may be sent to any one of the four editors. All other communications to the editors should be addressed to the managing editor, L. J. Paige at the University of California, Los Angeles 24, California.

50 reprints per author of each article are furnished free of charge; additional copies may be obtained at cost in multiples of 50 .

The Pacific Journal of Mathematics is published quarterly, in March, June, September, and December. The price per volume (4 numbers) is $\$ 12.00$; single issues, $\$ 3.50$. Back numbers are available. Special price to individual faculty members of supporting institutions and to individual members of the American Mathematical Society: $\$ 4.00$ per volume; single issues, $\$ 1.25$.

Subscriptions, orders for back numbers, and changes of address should be sent to Pacific Journal of Mathematics, 2120 Oxford Street, Berkeley 4, California.

Printed at Kokusai Bunken Insatsusha (International Academic Printing Co., Ltd.), No. 6, 2-chome, Fujimi-cho, Chiyoda-ku, Tokyo, Japan.

PUBLISHED BY PACIFIC JOURNAL OF MATHEMATICS, A NON-PROFIT CORPORATION

The Supporting Institutions listed above contribute to the cost of publication of this Journal, but they are not owners or publishers and have no responsibility for its content or policies. 


\section{Pacific Journal of Mathematics}

\section{Vol. 9, No. $2 \quad$ June, 1959}

Lee William Anderson, On the breadth and co-dimension of a topological lattice

Frank W. Anderson and Robert L. Blair, Characterizations of certain lattices

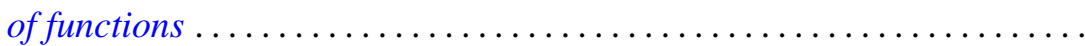

Donald Charles Benson, Extensions of a theorem of Loewner on integral

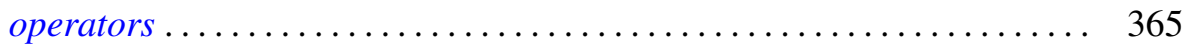

Errett Albert Bishop, A duality theorem for an arbitrary operator ........ 379

Robert McCallum Blumenthal and Ronald Kay Getoor, The asymptotic distribution of the eigenvalues for a class of Markov operators ........

Delmar L. Boyer and Elbert A. Walker, Almost locally pure Abelian

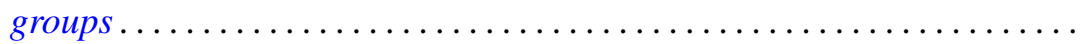

Paul Civin and Bertram Yood, Involutions on Banach algebras ........... Lincoln Kearney Durst, Exceptional real Lehmer sequences .... 415

Eldon Dyer and Allen Lowell Shields, Connectivity of topological

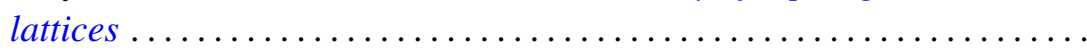

Ronald Kay Getoor, Markov operators and their associated

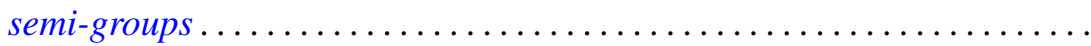

Bernard Greenspan, A bound for the orders of the components of a system of algebraic difference equations

Branko Grünbaum, On some covering and intersection properties in

Minkowski spaces ............................

Bruno Harris, Derivations of Jordan algebras ..............

Henry Berge Helson, Conjugate series in several variables.

Isidore Isaac Hirschman, Jr., A maximal problem in harmonic analysis.

II .

Alfred Horn and Robert Steinberg, Eigenvalues of the unitary part of a matrix

Edith Hirsch Luchins, On strictly semi-simple Banach algebras ...

William D. Munro, Some iterative methods for determining zeros of

functions of a complex variable...

John Rainwater, Spaces whose finest uniformity is metric .

William T. Reid, Variational aspects of generalized convex functions ....

A. Sade, Isomorphisme d'hypergroupoï des isotopes ...... . .

Isadore Manual Singer, The geometric interpretation of a special

connection . . .

Charles Andrew Swanson, Asymptotic perturbation series for characteristic

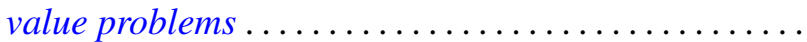

